\title{
Evaluation of Genetic Diversity and Identification of Huperzia Species Collected in Some Different Areas in Vietnam by Molecular Markers
}

\author{
Tran Thi Thu $\mathrm{Ha}^{1}$, Tran Dang Khanh ${ }^{2,3}$, Khuat Huu Trung ${ }^{2^{*}}$ \\ ${ }^{1}$ Institute of Forestry Research and Development, Thai Nguyen University of Agriculture and \\ Forestry, Vietnam; \\ ${ }^{2}$ Agricultural Genetics Institute, North Tu Liem, Hanoi, Vietnam; \\ ${ }^{3}$ Center for Expert, Vietnam National University of Agriculture, Trau Quy, Hanoi, Vietnam; \\ ${ }^{*}$ Corresponding author: khuathuutrung@yahoo.com
}

Keywords: Huperzia, Lycopodiaceae family, ITS, gene sequence, species

\begin{abstract}
The objective of this study was to evaluate genetic diversity of 35 Huperzia samples collected from the different geographical areas in Vietnam by using $r b c \mathrm{~L}$ markers. The results revealed that the samples were genetically diverse in high genetic similarity which ranged from 98.0 to $99.0 \%$, respectively. Based on the Genbank data in comparison, it was ascertained that only one sample (BK3) is a member of H.phlegmarioides group, and others belonged H. squarrosa group as divided into two main groups by phylogenetic tree analyses. It suggests that some Huperzia samples may plausibly descend from the same origin, evolution and arising relations. This study has provided useful information for further identifying the high-quality genetic plant sources for propagation, development and conservation of the high-valued medicinal materials of Huperzia plants in this country.
\end{abstract}

\section{Introduction}

Huperzia species such as H. squarrosa (HS) or Lycopodium squarrosum (LS) species belongs to the family of Lycopodiaceae. This species is widely distributed in many countries in the world, and available in the tropical and temperate regions with over 415 species in global [1]. They are adapted in mountainous regions with the height from 1000 to $3000 \mathrm{~m}$ above sea level [2]. In Vietnam, these plants are well-defined as high tolerance to heat, drought and growing in thin forests. They are also obtainable in some places from the North to the Centre of this country [3] and are easily found in the moist forests and rainforests at high altitude in and amongst mosses and other angiosperms epiphytes [4]. The major morphological characteristics of H. squarrosa were narrated as shown in Figure 1. The stem is pendulous and up to $60 \mathrm{~cm}$ long, branching regularly dichotomous and isotomous; their leaves microphyllous, spirally arranged, not imbricated and sharply acute, entire, rigid, coriaceous, shining, veins simple with no branches or unions extended to a middle portion (Figure $1 \mathrm{~A}, \mathrm{~B}$ ).
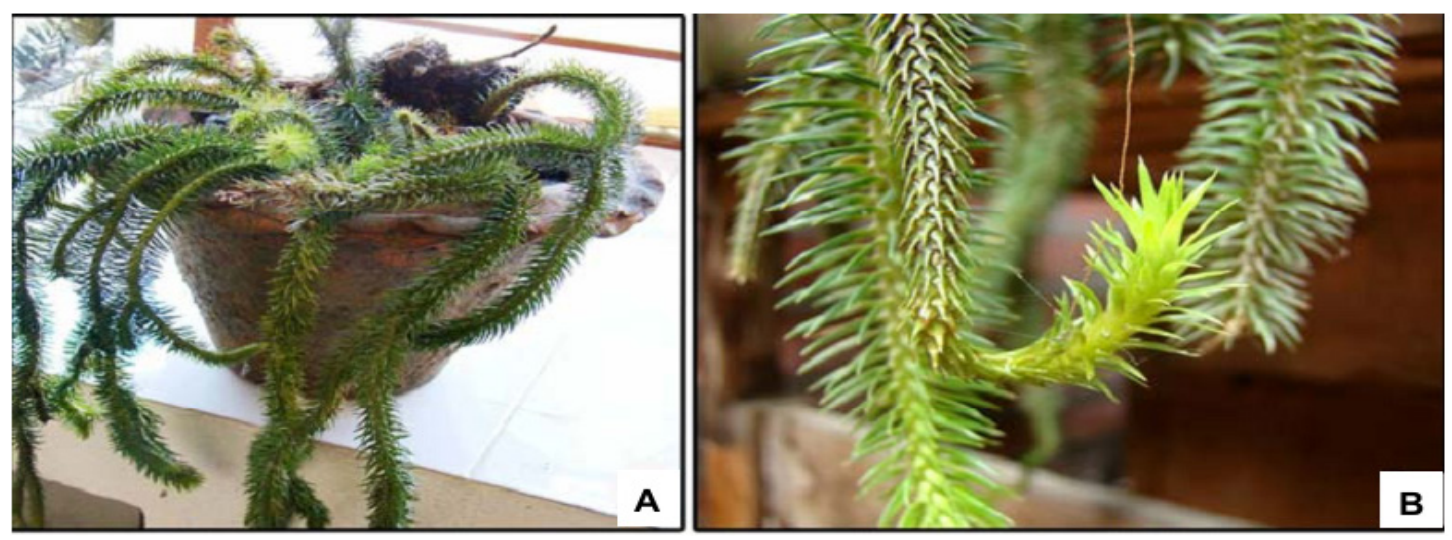

Figure 1. Morphological structures of the sporophytic body in H. squarrosa (G.Forst) Trev.

A: Habit; B: upward turned stem [4] 
H. squarrosa is known as a highly valuable medicinal plant, which contains alkaloids, flavones, triterpenes, phenolic acids, especially including Huperzine A (Hup A), Huperzine B (Hup B), N-methyl-huperzine B, Huperzinine, Lycoporine A, Carina-tumine A, etc [5]. To the best of our knowledge, over 300 Lycopodium alkaloids have been reported [6]. According to the report of Ngoc et al [7], the alkaloids isolated from H. squarrosa collected from Lam Dong province Vietnam includes 6 main compounds: lycosquarosine A, acetylaposerratinine, huperzine A, huperzine B, 8 $\alpha$-hydrophlemariurine B and huperzinine which may account for the effectiveness of this plant in the treatment of several brain diseases [8].

This plant is traditionally used to treat many ailments like cold, fever, bruises, pain, strains, contusion, stasis swelling, rheumatism etc. The numerous studies on pharmacological effects have been done such as anticonvulsant, anti-inflammatory, antioxidant, anti-aoptosis, and organophosphate poisoning myasthenia gravis [9]. Interestingly, this plant has enhanced the neurotransmitters, prevent plaque formation, tangles in the brain, feed and nourish brain cells, which positive response to Alzheimer's, Parkinson's, brain atrophy and dementia and diseases related to brain nerve damage, preventing memory decline or brain atrophy [10-13].

The Internal Transcribed Spacer (ITS) is one of the most popular tools and widely used DNA fragments in plant molecular systematics at the genetic and molecular species levels due to its potentially high resolution of inter-and intraspecific relationship [14]. The ITS region is argued to be useful for low-level phylogenetic analysis because of its relatively fast rate of evolution [15]. Moreover, ITS is considered as one of the most feasible molecular markers for angiosperm phylogenetic inference and genetics relatedness which is a proven useful source of characteristics for phylogenetic studies in the plant kingdom [16]. In the current application, DNA sequences from a standardized gene region are possibly generated from a small tissue sample taken from the known species [17]. Typically, ITS sequences have provided the molecular evidence to evaluate the phylogeny of several taxonomic groups from the genus and subfamily of the plants.

In the world, Huperzia is listed in a red book as an endangered plant [18]. In Vietnam, this is one of the rarest species carrying precious genetic resources, which are being degraded and also included in the red book that needs to be protected, developed and appropriately exploited. However, in Vietnam, customarily, the botanists have identified and classified the relatedness of the valuable species based on the morphological and cytological characteristics. The disadvantages of these methods are restricted due to the environmental effects and diagnostic resolution. Hence, the objective of this study was to assess the genetic diversity and identification of 35 samples collected from different areas by using $r b c \mathrm{~L}$ markers. In this study, the sequences of the chloroplast gene ribulose-1-5-bisphosphate carboxylase/oxygenase $(r b c \mathrm{~L})$ were to use for genetic variation and identification of the Huperzia samples.

\section{Materials and Methods}

\section{Materials collection}

A total of 35 samples of Huperzia species was collected in the different provinces in Vietnam. The detail information of the samples as shown in Table 1. 
Table 1. List of the collected Huperzia samples used in this study

\begin{tabular}{|c|c|c|c|c|c|}
\hline No & Origin & Code & No & Origin & Code \\
\hline 1 & Cho Moi - Bac Kan & BK1 & 19 & Tram Tau - Yen Bai & YB1 \\
\hline 2 & $\mathrm{Na} \mathrm{Ri}-\mathrm{Bac}$ Kan & $\mathrm{BK} 2$ & 20 & Van Tran - Yen Bai & YB2 \\
\hline 3 & Cho Don - Bac Kan & BK3 & 21 & Luc Yen - Yen Bai & YB3 \\
\hline 4 & Thai An - Quan Ba - Ha Giang & HG1 & 22 & Lam Binh - Tuyen Quang & TQ1 \\
\hline 5 & Vung Tai - Quan Ba-Ha Giang & HG2 & 23 & Na Hang-Tuyen Quang & TQ2 \\
\hline 6 & Viet Lam - Vi Xuyen - Ha Giang & HG3 & 24 & Ham Yen-Tuyen Quang & TQ3 \\
\hline 7 & Tra Linh - Cao Bang & CB1 & 25 & Sa Pa- Lao Cai & $\mathrm{LC} 1$ \\
\hline 8 & Nguyen Binh - Cao Bang & $\mathrm{CB} 2$ & 26 & Van Ban- Lao Cai & $\mathrm{LC} 2$ \\
\hline 9 & Trung Khanh - Cao Bang & CB3 & 27 & Muong Khuong- Lao Cai & LC3 \\
\hline 10 & La Hien - Vo Nhai - Thai Nguyen & TN1 & 28 & That Khe-Lang Son & LS1 \\
\hline 11 & Quy Ky - Thai Nguyen & TN2 & 29 & Huu Lung -Lang Son & LS2 \\
\hline 12 & $\begin{array}{c}\text { Sang Moc - Vo Nhai - Thai } \\
\text { Nguyen }\end{array}$ & TN3 & 30 & Loc Binh -Lang Son & LS3 \\
\hline 13 & Doan Hung - Phu Tho & PT1 & 31 & Tay Thien-Vinh Phuc & VP1 \\
\hline 14 & Tan Son - Phu Tho & PT2 & 32 & $\begin{array}{c}\text { Phong Nha-Ke Bang-Quang } \\
\text { Binh }\end{array}$ & QB1 \\
\hline 15 & Yen Lap - Phu Tho & PT3 & 33 & Quynh Nhai-Son La & SL1 \\
\hline 16 & Sin Ho - Lai Chau & LCH1 & 34 & Hoa Binh & HB1 \\
\hline 17 & Muong Te - Lai Chau & LCH2 & 35 & Vang Vieng - Laos & TDL \\
\hline 18 & Tam Duong - Lai Chau & LCH3 & & & \\
\hline
\end{tabular}

Total DNA extraction and amplification of $r b c L$

The fresh samples were collected and intermediately transferred to the laboratory for DNA extraction. In this study, DNA extract was done following the CTAB method of Doyle and Doyle [19] with some minor modifications. The yielded DNA products were then confirmed and determined by the use of Spectrophotometer [20]. The forward primer $r b c \mathrm{~L}-\mathrm{F}$ was 5'ATGTCACCACAAACAGAGACTAAAGC-3' and the reverse primer $r b c \mathrm{~L}-\mathrm{R}$ was 5'CTTCTGCTACAAATAAGAATCGATCTC-3', respectively.

Amplification was made in a polymerase chain reaction (PCR) in the tuber $0.2 \mathrm{ml}$ with total volume $(15 \mu \mathrm{l})$, of which contained $9.0 \mu \mathrm{l}$ deionized distilled water, buffer $\mathrm{Mg}+25 \mathrm{Mm}(1.5 \mu \mathrm{l})$, dNTPs $10 \mathrm{Mm}(0.3 \mu \mathrm{l})$, Taq ADN polymerase $5 \mathrm{U} / \mu \mathrm{l}(0.2 \mu \mathrm{l})$, ITS1 $10 \mu \mathrm{M}(1.5 \mu \mathrm{l})$, ITS8 $10 \mu \mathrm{M}$ $(1.5 \mu \mathrm{l})$ and DNA $50 \mathrm{ng} / \mu \mathrm{l}(1.0 \mu \mathrm{l})$, respectively. PCR program was performed as the method described by Trung et al [15]. Briefly, denaturation was made for $94^{\circ} \mathrm{C}, 56^{\circ} \mathrm{C}$ for annealing, and $72^{\circ} \mathrm{C}$ for extension and $72^{\circ} \mathrm{C}$ for the final extension. Gel removal Qiagen Kit was applied for PCR products.

\section{ITS sequencing and phylogenetic analysis}

Sequencing was carried out at Macrogen company (Korea) by applying ABI PRISM 3700 DNA Analyzer (Applied Biotech). The data were used to analyze by MEGA 5 software to generate 
a phylogenetic tree with neighbour-joining (NJ) methods. BLAST tool was used to compared the obtained sequences to National Center for Biotechnology Information databases (NCBI).

\section{Results and Discussion}

Molecular markers application to identify Huperzia samples based on ITS region sequences

Recently, the advances in molecular systematics in the plants have been significantly improved. The chloroplast gene ribulose-1-5-bisphosphate carboxylase/oxygenase for the large subunit of $r b c \mathrm{~L}$ located on the chloroplast genome which is a proper use for the interference of phylogenetic relationships at the higher taxonomic levels [21]. Moreover, it is conspicuous that the molecular approach has been powerful and accuracy for phylogenetic analysing in the plant which is arduous to decipher by phenotyping. Hence, in this study, a total of 35 samples were collected and analysed by $r b c \mathrm{~L}$ markers. The DNAs of 35 samples of Huperzia species had enough high concentration and quality for further experiments. All bands were clean and enough quality for further experiment. PCR reaction was performed with the primers $r b c \mathrm{~L}$. The results showed that 35 samples of Huperzia were a single-form band with the size of 650 bp (Figure 1), which was a resemblance to the report of Sundary and Papuangan [22] who applied the $r b c \mathrm{~L}$ gene for analysing of Syzygium aromaticum.

The purified PCR products with the primers $R b c \mathrm{~L}$ were directly analyzed by use of the ABI PRISM 3700 DNA Analyzer (Applied Biotech) of Macrogen company (Korea) and MEGA v5.1 software. The sequences of leaf samples were compared to the published NCBI reference sequences (corresponding to each species) using Blast tool (Basic Local Alignment Search Tool).

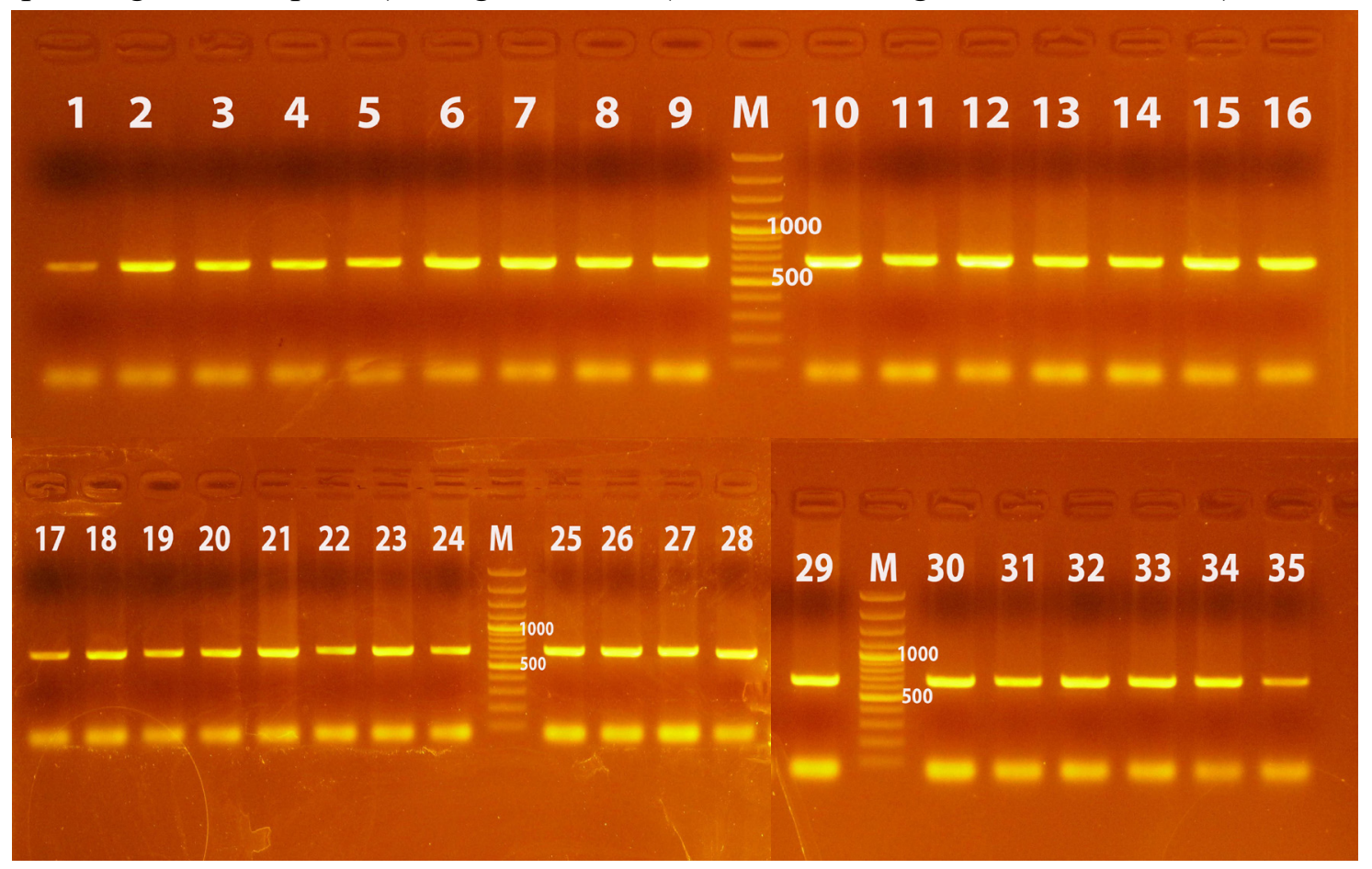

Figure 2. PCR products of the $H$. squarrosa samples with pair primers $R b c \mathrm{~L}-\mathrm{F} / R b c \mathrm{~L}-\mathrm{R}$; M: Marker $100 \mathrm{bp}$ plus DNA

The results showed that the sequences of 35 samples had a similar percentage from $98.0 \%$ to $99.0 \%$ in comparison to NCBI. In particular, 02 Huperzia samples having $98.0 \%$ of similarity to NCBI references (PT2 and LC3) were identified. The remaining 33 samples showed a similar percentage of $99,0 \%$ in comparing to Genbank (DQ464235.1 and AJ133896.1) as indicated in Table 1. Our obtained results were similar to some previous studies to use $r b c \mathrm{~L}$ to identify the higher taxonomic levels [23-24]. 
Table 2. Comparison of ITS sequences of 35 Huperzia samples on Blast (http://blast.ncbi.nlm.nih.gov/Blast.cgi)

\begin{tabular}{|c|c|c|c|c|}
\hline No & Code & Taxon & GenBank Accession No. & ID $(\%)$ \\
\hline 1 & BK1 & Huperzia squarrosa & DQ464235.1 & 99.0 \\
\hline 2 & $\mathrm{BK} 2$ & Huperzia squarrosa & DQ464235.1 & 99.0 \\
\hline 3 & BK3 & Huperzia phlegmarioides & AJ133896.1 & 99.0 \\
\hline 4 & HG1 & Huperzia squarrosa & DQ464235.1 & 99.0 \\
\hline 5 & HG2 & Huperzia squarrosa & DQ464235.1 & 99.0 \\
\hline 6 & HG3 & Huperzia squarrosa & DQ464235.1 & 99.0 \\
\hline 7 & $\mathrm{CB} 1$ & Huperzia squarrosa & DQ464235.1 & 99.0 \\
\hline 8 & CB2 & Huperzia squarrosa & DQ464235.1 & 99.0 \\
\hline 9 & CB3 & Huperzia squarrosa & DQ464235.1 & 99.0 \\
\hline 10 & TN1 & Huperzia squarrosa & DQ464235.1 & 99.0 \\
\hline 11 & TN2 & Huperzia squarrosa & DQ464235.1 & 99.0 \\
\hline 12 & TN3 & Huperzia squarrosa & DQ464235.1 & 99.0 \\
\hline 13 & PT1 & Huperzia squarrosa & DQ464235.1 & 99.0 \\
\hline 14 & PT2 & Huperzia squarrosa & DQ464235.1 & 98.0 \\
\hline 15 & PT3 & Huperzia squarrosa & DQ464235.1 & 99.0 \\
\hline 16 & LCH1 & Huperzia squarrosa & DQ464235.1 & 99.0 \\
\hline 17 & $\mathrm{LCH} 2$ & Huperzia squarrosa & DQ464235.1 & 99.0 \\
\hline 18 & $\mathrm{LCH} 3$ & Huperzia squarrosa & DQ464235.1 & 99.0 \\
\hline 19 & YB1 & Huperzia squarrosa & DQ464235.1 & 99.0 \\
\hline 20 & YB2 & Huperzia squarrosa & DQ464235.1 & 99.0 \\
\hline 21 & YB3 & Huperzia squarrosa & DQ464235.1 & 99.0 \\
\hline 22 & TQ1 & Huperzia squarrosa & DQ464235.1 & 99.0 \\
\hline 23 & TQ2 & Huperzia squarrosa & DQ464235.1 & 99.0 \\
\hline 24 & TQ3 & Huperzia squarrosa & DQ464235.1 & 99.0 \\
\hline 25 & $\mathrm{LC} 1$ & Huperzia squarrosa & DQ464235.1 & 99.0 \\
\hline 26 & $\mathrm{LC} 2$ & Huperzia squarrosa & DQ464235.1 & 99.0 \\
\hline 27 & LC3 & Huperzia squarrosa & DQ464235.1 & 98.0 \\
\hline 28 & LS1 & Huperzia squarrosa & DQ464235.1 & 99.0 \\
\hline 29 & $\mathrm{LS} 2$ & Huperzia squarrosa & DQ464235.1 & 99.0 \\
\hline 30 & LS3 & Huperzia squarrosa & DQ464235.1 & 99.0 \\
\hline 31 & VP1 & Huperzia squarrosa & DQ464235.1 & 99.0 \\
\hline 32 & QB1 & Huperzia squarrosa & DQ464235.1 & 99.0 \\
\hline 33 & SL1 & Huperzia squarrosa & DQ464235.1 & 99.0 \\
\hline 34 & HB1 & Huperzia squarrosa & DQ464235.1 & 99.0 \\
\hline 35 & TDL & Huperzia squarrosa & DQ464235.1 & 99.0 \\
\hline
\end{tabular}

As the results attained, it demonstrated that 35 samples collected from different geographical provinces were accurately the Huperzia species. The next step was to confirm at the molecular level by comparing the sequences of each species by using the corresponding reference species in both location and length of nucleotides applying the MEGA v5.1 software (Table 3 and Figure 3). 
Table 3. Sequence length analyses of total nucleotides of the 35 Huperzia samples

\begin{tabular}{|l|l|l|l|l|l|}
\hline No & $\begin{array}{c}\text { Sample } \\
\text { code }\end{array}$ & $\begin{array}{c}\text { Total of } \\
\text { Nucleotides }\end{array}$ & No & $\begin{array}{c}\text { Sample } \\
\text { code }\end{array}$ & $\begin{array}{c}\text { Total of } \\
\text { Nucleotides }\end{array}$ \\
\hline 1 & BK1 & 615 & 19 & YB1 & 614 \\
\hline 2 & BK2 & 615 & 20 & YB2 & 613 \\
\hline 3 & BK3 & 616 & 21 & YB3 & 616 \\
\hline 4 & HG1 & 616 & 22 & TQ1 & 613 \\
\hline 5 & HG2 & 616 & 23 & TQ2 & 615 \\
\hline 6 & HG3 & 616 & 24 & TQ3 & 613 \\
\hline 7 & CB1 & 614 & 25 & LC1 & 615 \\
\hline 8 & CB2 & 613 & 26 & LC2 & 614 \\
\hline 9 & CB3 & 614 & 27 & LC3 & 614 \\
\hline 10 & TN1 & 615 & 28 & LS1 & 613 \\
\hline 11 & TN2 & 615 & 29 & LS2 & 614 \\
\hline 12 & TN3 & 616 & 30 & LS3 & 615 \\
\hline 13 & PT1 & 614 & 31 & SL1 & 616 \\
\hline 14 & PT2 & 613 & 32 & HB1 & 615 \\
\hline 15 & PT3 & 613 & 33 & TDL & 614 \\
\hline 16 & LCH1 & 615 & 34 & VP1 & 614 \\
\hline 17 & LCH2 & 615 & 35 & QB1 & 613 \\
\hline 18 & LCH3 & 618 & & & \\
\hline
\end{tabular}

The data shown in Table 3 disclosed that the sequence lengths of the samples were consistent with the results of the PCR band size as presented in Figure 3. 


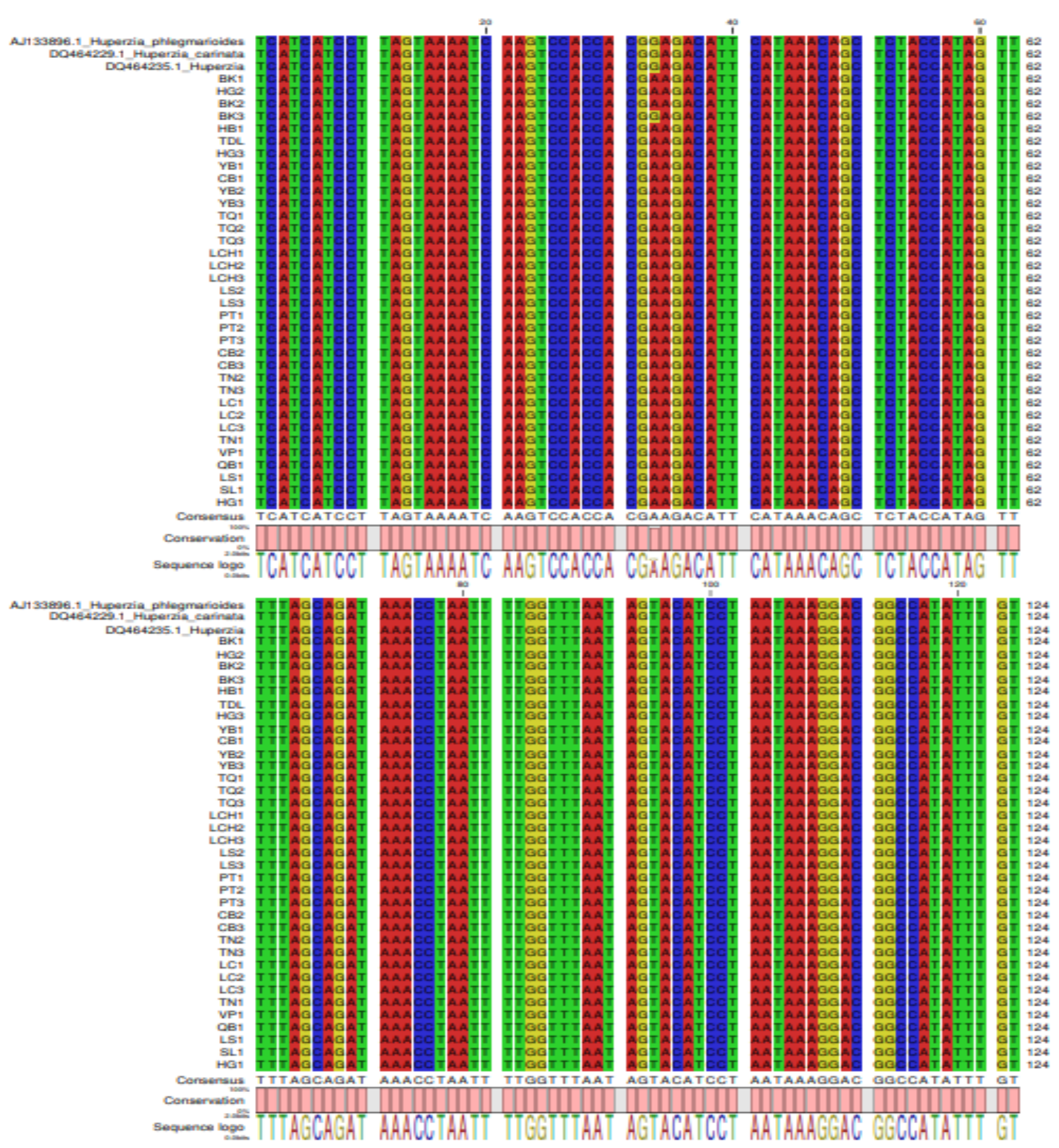

Figure 3. Comparison of a nucleotide sequence of 35 Huperzia samples with the reference sequence species

In comparing to the database from the NCBI Genbank, the results of 35 Huperzia samples were highly similar to the corresponding sequences. Additionally, they were consistent with the results when comparing nucleotide sequences to find the corresponding species via Blast (http://blast.ncbi.nlm.nih.gov/Blast.cgi).

Among them, there was only one sample (BK3) belonging to H.phlegmarioides group, and the others of the 34 samples were clustered in H.squarrosa group, respectively (Figure 3 and Figure 4). In the fact that the available databases on the $r b c \mathrm{~L}$ gene are very useful and facilitated to identify phylogenetic relationships of many plant species at interfamilial levels [25, 22]. Dubisson [26] successfully applied $r b c \mathrm{~L}$ sequences of 18 species of the fern genus Trichomanes for assessing their systematic relationships which showed a more accurate reflection of the generic concept applied to other fern and angiosperms. 
Genetic diversity and genetic relationships between the 35 samples of Huperzia samples

The data in Table 3 showed that the sequences of 35 Huperzia samples had a high similarity. The phylogenetic tree of 35 Huperzia samples was generated by using the Mega 6.0 software following the Maximum likelihood method (Figure 4). The results of the polygenetic relationship analysis have revealed that the phylogenetic tree divided 35 Huperzia samples into two main different clusters:

The first cluster included the sequences of 34 Huperzia samples and reference species of H.squarrosa (DQ464235.1 on GenBank). The samples in this group had very high genetic similarity in comparing to the reference species in a range from $95.47 \%$ (between the LCH3 sample with the reference species) to $96.25 \%$ (between the samples YB2, TQ1, TQ3, PT2, PT3, CB2, QB1 and LS1 with reference species), respectively.

The second cluster comprised the sequence of the Huperzia sample of BK3 (collected from the Cho Don - Bac Kan) which was matching with H. phlegmarioides (AJ133896.1 on GenBank) and H.carinata (DQ464229.1 on GenBank) in the same branch. The genetic similar coefficient of this sample was $95.62 \%$ in comparing to the reference species $H$. phlegmarioides was $94.81 \%$ to compare with the reference species H.carinata.

To the best our knowledge, over 251 plant species have been successfully applied and reached $100 \%$ by use of two primary types [27, 22], and acquired a greater length (around 1.428 to $2500 \mathrm{bp}$ ) by applying full-length $r b c \mathrm{~L}$ [28]. Additionally, Kesanakuthi et al [29] used $r b c L$ sequence alone to investigate $85 \%$ plant species groups of all root samples, and spelling out the ecological factors that contributed to the subterranean spatial organization of plant diversity in nature. By using datasets of Genbank, some works used the blast algorithm to examine the ability of $r b c \mathrm{~L}$ as well as various combination of the nuclear ribosomal ITS and 5.8S regions to make accurate identification in land plants species [30-31]. Moreover, ptDNA markers, ITS such as ITS2 has had great effective DNA barcoding marker with over $92 \%$ successful identification in 6600 plant samples [32]. Also, some recent reports have ascertained that using $r b c \mathrm{~L}+$ matK as the standard barcode for the flora of moderate phylogenetic dispersion was up to $92 \%$ of the species that could be differentiated the plant kingdom [33-34].

In this study, based on region sequences, a total of 35 Huperzia samples were successfully in analysed their species-level identification by using $r b c \mathrm{~L}$ primers and compared NCBI Genbank databases. However, due to the lack of species-level variation which may hinder species-level identification. Therefore, it should be applied $r b c \mathrm{~L}$ combining ITS, $m a t \mathrm{~K}, t r n \mathrm{H}-p s b \mathrm{~A}$ for specieslevel accuracy identification of the plants. Moreover, some specifically different DNA regions from both the plastid genome such as $r b c \mathrm{~L}, r p o \mathrm{~B}, r p o \mathrm{C} 1, m a t \mathrm{~K}, y c f 1$ and $t r n \mathrm{H}-p s b \mathrm{~A}$ and nuclear genome ITS should be further applied for accurate identification of various species. 
Table 4. Genetic homology coefficients between the 35 Huperzia samples

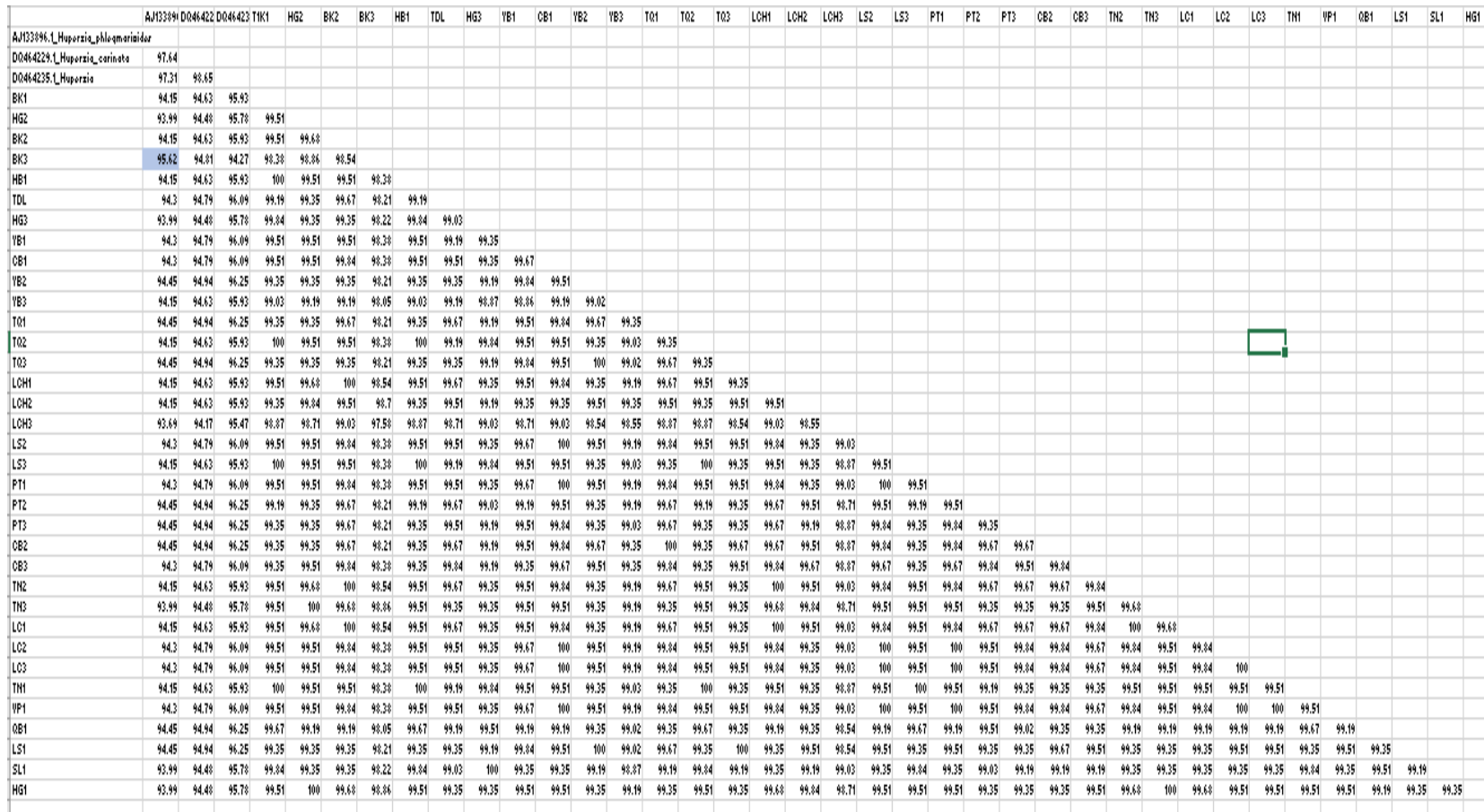

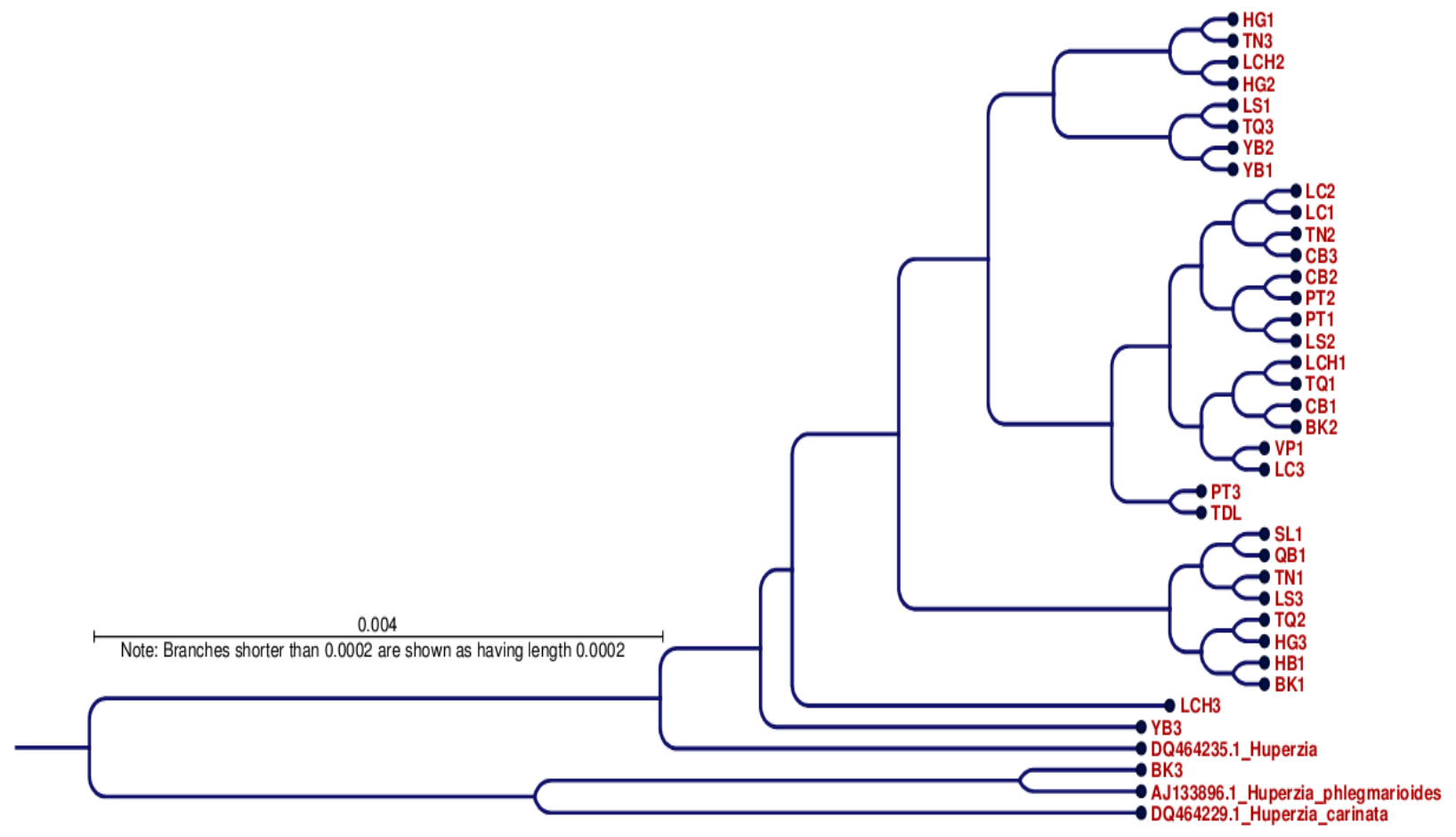

Figure 4. Generated phylogenetic tree species of 35 Huperzia samples with the reference species 


\section{Conclusions}

All the Huperzia samples collected from some different geographical provinces in Vietnam had similar ITS sequences in compare to NCBI corresponding library reference. Via the application of chloroplast region sequence with the $R b c \mathrm{~L}-\mathrm{F} / R b c \mathrm{~L}-\mathrm{R}$ primers, a total of 34 samples was identified as the group of $H$. squarrosa species (DQ464235.1 on GenBank) with the range from 95.47\% to $96.25 \%$. The Huperzia sample of BK3 collected from Cho Don - Bac Kan was grouped as $H$. phlegmarioides species with a similar coefficient of $95.62 \%$.

\section{References}

[1] Singh, H. B. and K. Singh. (2010). Huperzia serrata: a promising medicinal pteridophyte from North East India. NeBIO, 1: 27-34.

[2] Maridass M. and G. Raju (2009). Investigation of Phytochemical and Antimicrobial Activity of Huberzia Species. Pharmacol, 3: 688-692.

[3] Xuyen, D.T. (2013), Current status of plant defects in Kon Ka Kinh National Park, Gia Lai Province, 5th National Scientific Conference on Ecology and Biological Resources.

[4] Yumkham, S.D., and P.K. Singh, (2011). Huperzia squarrose (G.Forst.) Trev. (Lycopodiaceae) in Manipur: Taxonomy and biological aspects. Taiwania, 56(2): 157-164.

[5] Sahidan N., C. Y., Choo Latiff A., R. Jaman. (2012). Variations of huperzine A content in Lycopodiaceae species from tropics. Chin. J. Nat. Med. 10, 125-128.

[6] Nilsu, T., W. Thaisaeng, W. Thamnarak, C. Eurtivong, A. Jumraksa, S. Thorroad, N. Khunnawutmanotham, S. Ruchirawat, N. Thasana. (2018). Three Lycopodium alkaloids from Thai club mosses. Phytochem, 156: 83-88.

[7] Ngoc, V.T., P.T. Hanh, L.T.L. Anh, N.T.Dat, L.T.B. Thuy. (2016). Qualification and quantification of Huperzine a from Huperia serrata in Dalat, Lamdong province. J.Biotech, 14(3): 473-478.

[8] Nguyen, H.T., H.T. Doan, D.V. Ho, K.T. Pham, A. Raal, H. Morita. (2018). Huperphegmines $\mathrm{A}$ and $\mathrm{B}$, two novel Lycopodium alkaloids with an unprecedented sketon from Huperzia phlegmaria, and their acetylchlinesterase inhibitory activities. Fitoterapia, 129:267-271.

[9] Jaswinder, K., S. Rajmeet, S. Gurinder, K. Harpreet, K. Jasvir, K.Manpreet, S. Parminder, K. Jaspreet. (2016). A systematic review on Huperzia serrata. Inter. J.Pharmaco. Phytochem. Res, 8 (8): 1250-1255.

[10] Wang, Z.F., and X.C.Tang. (2007). Huperzine A protects C6 rat glioma cells against oxygenglucose deprivationinduced injury. FEBS Lett, 581:596-602.

[11] Thorroad, S., P. Worawittayanont, N.Khunnawutmantham, N.Chimnoi, A.Jumruksa, S.Ruchirawat, N.Thasana. (2014).Three new Lycopodium alkaloids from Huperzia carinata and Huperzia squarrosa. Tetrahedron,70:8017-8022.

[12] Nguyen N. C., and C. L. Tran. (2014). Isolation of huperzine A from Huperzia squarrosa (Forst.) Trevis., Lycopodiaceae, J.Med. Mat, 19 (1):22-27.

[13] Zhao X. M., Z. Q. Wang, S. H. Shu, W. J. Wang, H. J. Xu, Y. J. Ahn, M. Wang, X. Hu. (2013). Ethanol and methanol can improve Huperzine A production from Endophytic colletotrichum gloeosporioides. PLoS One 8:4, e61777.

[14] Yuan, Q.J., B.Zhang, D.Jiang, W.J.Zhang, T.Y. Lin, N.H. Wang, S.J.Chiou, L.Q.Huang. (2015). Identification of species and materia medica within Angelica L. (Umbelliferae) based on phylogeny inferred from DNA barcodes. Mol.Ecol.Resour. 15(2):358-371. 
[15] Trung, K.H., T.D.Khanh, L.H.Ham, T.D.Duong, N.T.Khoa. (2013). Molecular phylogeny of the endangered Vietnamese Paphiopedilum species based on the internal transcribed spacer of the nuclear ribosomal DNA. Adv.Stud.Biol, 5(7):337-346.

[16] Parveen, I., H.K. Singh, S.Raghuvanshi, U.C. Pradhan, S.B. Babbar. (2012). DNA barcoding of endangered Indian Paphiopedilum species. Mol.Ecol.Resour, 12(1):82-90.

[17] Kress, W.J., and D.Erickson. (2007). A two-locus global DNA barcode for land plants: the coding rbcL gene complements the non-coding trnH-psbA spacer region. Plos One,6: e580.

[18] Benniamin, A., V. Irudayaraj and V. S. Manickam (2008). How to identify rare and endangered ferns and fern allies. EthnoBot. Leaflts. 12: 108-117.

[19] Doyle, J.J., J.L. Doyle. (1987). A rapid DNA isolation procedure for small quantities of fresh leaf tissue. Phytochem Bul, 19:11-15.

[20] Sambrook, J. and D.W. Russell. (2001) Molecular cloning: a laboratory manual. Vol. 2, 3rd edn. Cold Spring Harbor Laboratory Press, New York.

[21] Hasebe, M., T. Omori, M. Nakazawa, T. Sano, K. Iwatsuki. (1994). rbcL gene sequencing provide evidence for the evolutionary lineages of leptosporangiate ferns. Proc Nat Acad Sci USA, 91(12): 5730-5734.

[22] Sundari, N. and N.Papuangan. (2019). Amplication and analysis of $r b c$ L (Ribulose-1,5Bisphosphate carboxylase) of clove in Ternate island. Inter. Confer. Life. Sci. Tech, 276, 01206, doi:10.1088/1755-1315/276/1/012061.

[23] Nam, M, and O.M. Lee (2001). A comparative study of the morphological characters and sequence data of $r b c \mathrm{~L}$ gene in Cosmarium species. Algae, 16(4): 349-361.

[24] Rajaram, M.C, C.S.Y.Yong, J.A. Gansau, R. Go. (2019). DNA barcoding of endangered Paphiopedilum species (Orchidaceae) of Peninsular Malaysia. Phytotaxa, 387(2): 094-104.

[25] Gielly, L, and P. Taberlet, (1994). The use of chloroplast DNA to resolve plant phylogenies: noncoding versus $r b c \mathrm{~L}$ sequences. Mol. Biol. Evol, 11: 769-777.

[26] Dubuisson, J.Y. (1994). rbcL sequences: a promising tool for the molecular systematics of the fern genus Trichomanes (Hymenophyllaceae)?. Mol Phylog Evol 8: 128-138.

[27] Fazekas, A.J., Burgess, P.R.Kesanakurti, S.W. Graham, S.G. Newmaster, B.C.K.S. Husband, D.M. Percy, M. Hajibabaei, S.C.H. Barret, (2008). Multiple multilocus DNA barcodes from the plastid genome discriminate plant species. Plos One, 3, e2802.

[28] Kress, W.J., K.J.Wurdack, E.A.Zimmer, L.A.Weigt, D.H. Janzen. (2005). Use of DNA barcodes to identify flowering plants. Proc.Nat.Acad. Sci USA, 102: 8369-8374.

[29] Kesanakurti, P.R., A.J. Fazekas. K.S. Burgess, D.M. Percy, S.G.Newmaster, S.W. Graham, S.C. Barrett, M. Hajibabaei, B.C.Husband. (2011). Spatial patterns of plant diversity belowground as revealed by DNA barcoding. Mol Ecol, 20:1289-1302.

[30] Chase, M.W., N. Salamin, M. Wilkinson, J.M. Dunwell, R.P. Kesana-kurthi, N.Haidar, V. Savolainen. (2005). Land plants and DNA barcodes: short-term and long-term goals. Philos.Trans. R. Soc. Lond. B Biol. Sci.360: 1889-1895. PMID:16214746.

[31] Newmanster, S.G., A.J. Fazekas, S. Ragupathy. (2006). DNA barcoding in land plants: evaluation of $\mathrm{rbcL}$ in a multigene tiered approach. Ca.J.Bot. 84: 335-341.

[32] Chen, T., X.Chao, L.Lei, C.Li, Y.Zhang, S.Zhou. (2016). Barcoding the kingdom plantae: new PCR primers for ITS regions of plants with improved universality and specificity. Mol.Ecol.Resour,16:138-149.

[33] Kress, W.J., F.A. Erickson, F.A. Jones, N.G. Swenson, R. Perez, O. Sanjur, E. Bermingham. (2009). Plant DNA barcodes and a community phylogeny of a tropical forest dynamics plot in Panama. Proc.Nat. Acad. Sci USA, 106:18621-18626.

[34] Bell, K., V.M., Loeffler, B.J. Brosi. (2017). An rbcL reference library to aid in the identification of plant species mixtures by DNA metabarcoding. App.Plant Sci, 5(3) doi:10.3732/apps.1600110 